\title{
PHYSICIANS AND THE CHEMICAL ANALYSIS OF MINERAL WATERS IN EIGHTEENTH-CENTURY ENGLAND
}

by

NOEL G. COLEY*

Mineral waters often produce cures, which we in vain attempt to perform by the combinations in our shops; even altho' these waters contain nothing but iron ... (W. Cullen, 1773). ${ }^{1}$

PHYSICIANS in England had been curious about the active principles of natural mineral waters since the early seventeenth century, when the idea of visiting a spa to drink or bathe in the waters first became popular. After the Restoration, fashionable London society, led by the king and court, established the practice of visiting spas such as Tunbridge Wells, Epsom, or Bath during the summer. Doctors were quick to recognize the advantages of persuading patients to take the waters at their source under the supervision of a resident physician, whilst the patients themselves were often glad of an excuse for spending a month or two enjoying the social delights of the spa whilst submitting to the strict regimen and medical treatments prescribed to enhance the effects of the waters. Coming from the depths of the earth, the latter were commonly thought to bear mysterious qualities which would provide cures for stubborn diseases such as bladder-stone and gravel, gout, rheumatism, diabetes, scrofula, and skin complaints. The waters were so difficult to analyse that it remained unclear what medicinal substances they really contained, and their curative properties had generally been determined by trial and error. ${ }^{2}$ There were many contradictory views, and physicians relying upon their clinical records devised their own methods of using the waters. Consequently, conflicting advice was often pressed upon patients by rival physicians in pursuit of professional advantage and financial gain. Already by the beginning of the eighteenth century it had become clear that if mineral waters were to be used most effectively a better understanding of their chemical composition was essential.

It had long been the practice to examine mineral waters in three stages. First, their

*Noel G. Coley, M.Sc., Ph.D., Staff Tutor in History of Science, The Open University, South East Region, 230-232 London Road, East Grinstead, Sussex RH 19 1LA.

1 William Cullen, Lectures on the materia medica, Edinburgh, 1773, p. 190.

${ }^{2}$ The analysis of English mineral waters in the seventeenth century is discussed in Ferenc Szabadvàry, History of analytical chemistry, Oxford, Pergamon Press, 1966, pp. $29-40$ and passim; A. G. Debus, 'Solution analyses prior to Robert Boyle', Chymia, 1962, 8: 41-61; idem, The chemical philosophy, 2 vols., New York, Science History Publications, 1977, vol. 1, pp. 109-214, 197-199; N. G. Coley, " Cures without care". "Chymical physicians" and mineral waters in seventeenth-century English medicine', Med. Hist., 1979, 29: 191-214. 


\section{N. G. Coley}

physical characteristics (colour, smell, temperature, etc.) were noted as they issued from the ground; then chemical tests were applied both to the water and to the residue left after evaporation; and lastly the medicinal effects were observed. In the $1680 \mathrm{~s}$, Robert Boyle had proposed a method of organizing these simple procedures into a general scheme of analysis. ${ }^{3}$ It was also recognized that the curative properties of a mineral water depended not only upon the nature of the substances it contained, but on their proportions in the water, and efforts were made to estimate these so as to compare the potency of one water with another. ${ }^{4}$ There were, however, serious ambiguities due to confusion over the use and meaning of chemical terms. Thus, when Robert Wittie analysed the water at Scarborough Spa he claimed to have found five principles dissolved in it, viz., vitriol, iron, alum, nitre, and salt..$^{5}$ Of these, the last was traditionally thought to come from sea-water, the common origin of all springs, whilst the rest were taken up by the water in its passage through the rocks. The terms "salt" and "alum" often indicated no more than a salty or bitter taste, whilst "vitriol" and "nitre" each referred to a variety of ill-defined substances. Since ancient times "nitre" had been used variously for soda, potash, rock-salt, talc, borax, saltpetre, and other substances, " "vitriol" might mean green vitriol (ferrous sulphate), but was also equated with the so-called "essurine" acid which could assume many forms. ${ }^{7}$ In addition, natural waters were supposed to absorb a "mineral spirit" from the earth which escaped when they were exposed to the atmosphere, leaving them ineffective as medicines. Many of these confused notions persisted during the eighteenth century, and mineral water analysis remained unreliable; it was a subject in the uncharted hinterland between chemistry and medicine not quite respectable in either. Lingering alchemical theories about the formation and properties of minerals and "spirits" in the earth, coupled with inadequate chemical knowledge, engendered widespread scepticism about the validity of the analytical results obtained, whilst the vagueness which characterized the conclusions often encouraged physicians to express opinions

${ }^{3}$ R. Boyle, Short memoirs for the natural experimental history of mineral waters, London, 1684-85. For a discussion of Boyle's chemical tests see R. G. Neville, 'Was Boyle the first to use spot test analysis?', Isis, 1958, 44: 438-439; W. Eamon, 'New light on Robert Boyle and the discovery of colour indicators', Ambix, 1980, 27: 204-209.

4Samuel Derham, Hydrologia philosophica, or an account of Ilmington Water in Warwickshire, ..., Oxford, 1685. Derham's successful use of this water in treating scrofula led to the popularity of Ilmington as a fashionable health resort. For Derham, see $D N B$, vol. 5, p. 842 .

${ }^{5}$ R. Wittie, Scarborough Spaw: ..., York and London, 1667 (1st ed., York, 1660), pp. 137-139. Wittie derived his chemical ideas from Edward Jorden, $A$ discourse of natural bathes and mineral waters ... . London, 1631 (2nd ed., London, 1632).

' For a discussion of these terms see M. Crosland, Historical studies in the language of chemistry, London, Heinemann, 1962 (reprinted, New York and London, Dover Publications, 1978), pp. 73-77, 99-100, 104, 178, and passim. See also, G. Agricola, De re metallica (1556), translated by H. C. Hoover and L. H. Hoover, London, Mining Magazine, 1912 (reprinted, New York and London, Dover Publications, 1950), pp. 545-592.

'John French, The Yorkshire Spaw..., London, 1652, p. 54, ascribed the term to Helmont, but it is certainly older. It was still extant in the eighteenth century; J. J. Becher referred to a universal acid, or essurine spirit forming in the earth a universal solvent with an acidic nature like vinegar, Physica Subterranea, Leipzig, 1738, Bk. 1, pp. 41f. (see J. R. Partington, A history of chemistry, 4 vols, London, Macmillan, 1961-70, vol. 2 (1961), p. 650). Stahl equated the universal acid with vitriolic acid, J. Juncker, Élémens de Chymie; suivant les principes de Beker [sic] et de Stahl, trans. from the 2nd Latin ed. by Demachy, 6 vols., Paris, 1757, vol. 5, pp. 62f, 181, 237. 


\section{Physicians and the chemical analysis of mineral waters}

supporting extravagant claims for the curative potential of particular springs.

To many, unaware of the difficult chemical problems involved, it seemed that mineral water analysis ought to be a simple matter. Friedrich Hoffmann, the most influential writer on the subject in the early eighteenth century, declared ". . . there are in reality but few Principles of these waters ...", and it was commonly supposed that the "... original Principles or Elements of mineral waters are only four, viz., Earth, Air, Fire and Water ...".9 In fact, for the greater part of the century the four-element theory seemed an adequate and entirely appropriate foundation on which to base a study of these natural products. Earthy deposits were commonly seen at the sources of mineral springs and many waters were known to deposit earthy sediments if allowed to stand; the problem was to identify their constituents. They could be separated into soluble and insoluble parts amongst which salts, earths, and "sulphurs" were to be found. The element of fire seemed to show itself clearly in the warm waters of Bath, Bristol, and Buxton, and many other springs were known to maintain an even temperature all through the year, including the coldest months of the winter. Of the four elements, air proved most difficult to identify, although long before Joseph Black showed that "fixed air" could form part of certain earths, ${ }^{10}$ it had been recognized that most mineral waters contain volatile components. The sharp taste of effervescent waters (acidulae) had been ascribed to a volatile acid since Roman times, but it was often confused with the mineral spirit. Both were thought to be formed within the earth and to impart peculiar, possibly undiscoverable properties to the waters. Consequently, it was sometimes said that there was no point in mineral water analysis since it would be ". . . impossible to discover and exhibit those Materials in them, that work such remarkable Cures ..."."1

Having stated this view, Thomas Short, a Sheffield physician writing on the subject in 1734, rejected it and asserted that it would be both practicable and even easy to discover the volatile components through a more organized approach to chemical analysis. He was critical of most existing works on mineral waters, and as late as 1766 could still remark that the methods used to examine them had been "... confused, inconclusive and wide of the Purpose, in so much that it would be surprizing if the Examiners should have made any beneficial or instructive Discoveries ...".12

\footnotetext{
'P. Shaw, New experiments and observations upon mineral waters... extracted from his /F. Hoffmann's/ several essays upon the subject and illustrated with notes, London, 1731 (2nd ed., 1743), p. 60.

-Thomas Short, Institutes: or an introduction to the examination of mineral waters, proposing methods for discovering their impregnating principles with greater certainty and exactness than has hitherto been done, London, 1766, p. 5. No attribution of authorship on title-page, but Short refers to this work in his General treatise of various cold mineral waters in England . . . London, 1765. For Short, see DNB, vol. 18, p. 154.

$10 \mathrm{~J}$. Black, 'Experiments upon magnesia alba, quicklime and some other alcaline substances', Essays and Observations Physical and Literary, Edinb., 1756, 2: 157-225 (reprinted, Edinburgh, Alembic Club Reprints, 1944, no. 1).

${ }^{11} \mathrm{~T}$. Short, The natural experimental and medicinal history of the mineral waters of Derbyshire, Lincolnshire and Yorkshire, particularly those of Scarborough... together with the natural history of the earths, minerals and fossils through which the chief of them pass, London and Sheffield, 1734, preface, p. iii. J. Wynter gives a typical expression of this view, Cyclus metasyncriticus, London, 1725, p. 40, “... may not waters be impregnated ... by effluvia from mineral substances unknown to us, and therefore not discoverable by experiments? ..." (quoted by J. Wall, Phil. Trans. R. Soc. Lond., 1756, 44: 468).

12 Short, loc. cit., note 11 above.
} 
Even Hoffmann did not escape Short's censure, despite the fact that he had made several valuable discoveries. He was the first to recognize magnesium salts in mineral waters and show how they could be distinguished from salts of lime using sulphuric acid. ${ }^{13} \mathrm{He}$ also knew that iron was sometimes held in solution by "gas silvestre" (carbon dioxide) and that sulphur-bearing waters blacken silver. Short recognized Hoffmann's contributions to improve mineral water analysis, but his practice of examining the total sediment obtained by evaporation, without isolating its separate constituents, was, in Short's view, unsatisfactory. It had led Hoffmann to deny the traditional notion of acidulae because he had found that the sediments generally showed the properties of alkaline substances. Thus, they nearly always effervesced with acids and turned syrup of violets green, but Short remarked that, since limestone was usually present in the sediments, they could hardly fail to exhibit these properties. He considered that Hoffmann had made too few experiments and had based his conclusicns on inadequate evidence. ${ }^{14}$

In his own examination of the sediment left after evaporating Pyrmont water, Short found two distinct substances. One of these was neutral and, although present only in small proportions, could be crystallized from its solution in hot water. Short knew that salts could often be identified by the shape of their crystals but he did not use the microscope for this purpose. He also emphasized the need to discover the proportions of the various constituents in the water so that analyses could be used to determine the most effective dosages. ${ }^{15}$ Short was aware of the need for a method of analysis which could be applied to any mineral water and he strove to produce one, but without success. His Institutes (1766) summarized all his earlier work but remained a collection of separate tests rather than presenting a coherent method. ${ }^{16}$ Steeped in traditional modes of thought, he held that the solvent powers of mineral waters were due to the universal acid diffused throughout nature in earth, air, and water, giving rise to the acidity of fixed air as well as that of other common acids. The mineral spirit he regarded not as an identifiable constituent of the waters, but as the sum total of all their chemical and physiological properties.

\section{FIRST STEPS TOWARDS METHODICAL ANALYSIS}

Amongst the many English physicians who wrote on mineral waters in the

\footnotetext{
${ }^{13}$ Hoffmann described an unknown neutral salt which "... is bitter and gives a cold sensation when placed on the tongue and does not . . give a precipitate with vitriol." (quoted by Szabadvàry, op. cit., note 2 above, p. 32).

${ }^{14}$ Short also criticized others including his contemporary, Peter Shaw, who considered mineral waters to be alkaline, though he admits that "... Hoffmann affords more truth and greater certainty towards a natural history of mineral waters, than all his predecessors together. ..." Short, op. cit., note 9 above, p. vii. D. W. Linden also rejected Hoffmann's view that chalybeate waters contained alkaline salts, Treatise on the origin, nature and virtues of chalybeate waters and natural hot baths .... London, 1748, p. 3. For Hoffmann, see C. C. Gillispie (editor), Dictionary of scientific biography (hereinafter DSB), 24 vols., New York, Charles Scribner's Sons, 1970-76, vol. 6(1972), pp. 458-461.

is In addition to its medical uses, Short suggested that mineral water analysis might also provide geological information leading to the discovery of new deposits of limestone, metal ores, coal, etc., Short, op. cit., note 9 above, p. iii. The same point was made later by Richard Kirwan, An essay on the analysis of mineral waters, London, 1799, pp. 2-4.

${ }^{16}$ Short's reagents included aqueous solutions of silver nitrate, mercuric chloride, lead acetate, potassium carbonate, sulphuric and hydrochloric acids, ammonia, ammonium chloride, and vegetable colours,
} 
eighteenth century, Short's contemporary and rival Peter Shaw was one of the more influential. ${ }^{17}$ As a physician in Scarborough before moving to London in 1726, Shaw was aware both of the benefits to be gained from successfully promoting the medicinal virtues of spa waters and of the disputes about them, not least those which had concerned his own local spa in the previous century. Also, having published an idiosyncratic edition of Boyle's works in 1725 and an English translation of Bacon eight years later, ${ }^{18}$ he was familiar with their ideas about the experimental method, which he tried to apply in his own treatment of mineral water analysis. Many of his contemporaries, writing about mineral waters, were intent on impressing their readers with the weight of their scholarship. Their elegant prose is often filled with wordy disputes, polemics, quotations from ancient authors, and persuasive arguments. Such works were frequently used as vehicles for pursuing controversies between rival factions within the medical profession itself. Those who had entered medicine by way of apprenticeship to an apothecary claimed superior chemical knowledge, although they were generally despised by professional physicians who, with their classical learning, sprinkled their texts liberally with Greek and Latin references.

Shaw tried to avoid these wordy disputes which, he said, merely served to increase the length of works on mineral waters without adding to their usefulness. Instead, he endeavoured to be as factual and objective as possible, and his treatment of the subject was more pragmatic than that of most of his contemporaries. His results, based on physical observations, "contrived experiments", and inductive reasoning, led him to suspect "... that Mineral Waters are no more than common water impregnated with certain Mineral substances, capable of dissolving or lodging therein", ${ }^{19}$ and he classified these as salts, earths, sulphurs, and fumes or spirits. In spite of the inadequacies of contemporary natural philosophy and chemistry, Shaw maintained that the means of discovering the contents, virtues, and uses of these waters were already available if only they could be properly deployed. In fact, “... nothing more is wanting to compleat the work, than a prudent, scientifical, and guarded Manner of using these Means; or to speak plainly, the principal Thing required is the Art of Induction."20

Beginning his analyses with the traditional step of examining the water at the spring, Shaw noted its appearance, smell, taste, colour, temperature, and specific

\footnotetext{
together with alcoholic tinctures of fustic, logwood, galls, green tea, red roses, pomegranate, etc.

${ }^{17}$ Shaw, a fashionable London physician, was perhaps best known for his editions of Stahl, Boyle, and Bacon (note 18 below) and Boerhaave (note 22 below). Partington describes him as "a well-educated quack", Partington, op. cit., note 7 above, vol. 2 (1961), p. 759, yet he was considered an authority on mineral water analysis both for his own work on the subject and for his translation of Hoffman (note 8 above). For Shaw see W. Munk, The roll of the Royal College of Physicians of London, 3 vols., London, Royal College of Physicians, 1878, vol. 2, pp. 190-194; DNB, vol. 7, p. 1380; G. Oldham, J. Chem. Educ., 1960, 37: 417-419.

${ }^{18} \mathrm{P}$. Shaw, The philosophical works of the Hon. Robert Boyle, Esq., abridged, methodized and disposed under the general heads of physics, statics, pneumatics, natural history, chymistry and medicine. The whole illustrated with notes, containing the improvements made in the several parts of natural and experimental knowledge since his time, 3 vols., London, 1725; idem., The philosophical works of Francis Bacon, methodized and made English, London, 1733. (Shaw's translation of Novum organon was republished in 1802 and again in 1812.)

${ }^{19} \mathrm{P}$. Shaw, An enquiry into the contents, virtues and uses of the Scarborough Spaw waters, with the method of examining any other mineral water, London, 1734, p. 7.

${ }^{20}$ Ibid., p. 78.
} 


\section{N. G. Coley}

gravity - the latter by the direct comparison of weights ${ }^{21}$ (Table I). He then examined the solid residues left after evaporation, recognizing in them nine different soluble

\section{TABLE}

APPARATUS AND CHEMICALS NEEDED FOR THE ANALYSIS OF MINERAL WATERS ACCORDING TO PETER SHAW (ENQUIRY, 1734).

Mariner's compass

Exact scales and weights

Hydrostatical balance

Variety of glasses

Cements

Alcohol thermometer

Hand pump

Air pump

Microscopes

Armed loadstone or touched plate of iron

Distilled water

Crucibles

Melting furnace

Fluxes and flux powders

Various vegetables

Animal matters

Mineral matters

Artificial matters
3 sizes for weighing grains, drachms, and ounces

For determining specific gravity

Cylindrical, shallow for evaporation, vials, bottles, glass eggs, bolt-heads, retorts, and receivers for distillation, etc.

Rosin, sealing wax, wax/turpentine mixtures

For raising water samples from wells

For extracting gases from the water

For observing visible particles in single drops of water; shapes of crystals, etc.

To test for metallic iron in residues

To heat up dry residues

Strong heat to melt metals, etc.

Tartar, nitre, salt-petre, borax, iron filings, etc.

Syrup of violets, red roses, mallows, cloves, lignum nephriticum, etc.

Tests for iron - green tea, oak leaves, oak bark, pomegranate bark, balustian flowers, galls, etc.

Dried blood, blood serum, bladder- and gall-stones, gouty chalkstone, pus, urine, phlegm, lymph, etc.

Iron ore, marcasites, pyrites, limestone, alum, vitriol, sulphur, mercurial salts - may also be used to enhance the usefulness of mineral waters. Blackening of metallic silver or mercury indicates sulphur present

Fixed and volatile alkaline salts, salt and oil of tartar, spirits of hartshorn, spirit and oil of vitriol, spirits of salt and of nitre. Solutions of corrosive sublimate in water, pure silver in aq. fort.; sugar of lead in water; pure gold in aq. reg.; copper in aq. fort.; copper in sal ammoniac; iron in aq. fort., etc.

${ }^{21}$ Despite the fact that Boyle had already proposed the use of the hydrometer, Boyle, op. cit., note 3 above, p. 68, and that Shaw had included the Short memoirs in his edition of Boyle's works, op. cit., note 18 above. 


\section{Physicians and the chemical analysis of mineral waters}

salts. ${ }^{22} \mathrm{His}$ grasp of the experimental skills required to identify these may be glimpsed in his treatment of common salt. Beginning with silver nitrate solution, Shaw warned that, though this was a delicate test for common salt, it could not be taken as exclusive proof since there might be other salts not yet known which also precipitate the silver solution. To identify common salt in the presence of other salts, he therefore heated the residue with oil of vitriol, comparing the result with similar tests on mixtures of common salt with nitre, salt of tartar (potassium carbonate), Epsom salt, borax, and alum. The final confirmation of the presence of common salt came from the cubical shape of its crystals viewed under the microscope.

To obtain the insoluble earthy residue, Shaw evaporated a large quantity of the mineral water to dryness, boiled the residue with pure water, filtered, and repeated the process several times to ensure that the final residue contained only insoluble matter. He grouped the earths into three classes, calcareous, stony, and ochry. The first effervesced with acids, produced a caustic lump like lime when burned, and would not melt in the strongest heat. Stony residues remained last after many washings, looked like sand and melted into a glass when heated with fixed alkali, whilst ochry earths could be recognized by their yellow colour and formation of little beads of iron on fusion. Other insoluble residues included the "sulphurs" - brimstone, orpiment, petroleum, and bitumen. Of these Shaw was concerned only with the first, which melted readily over the fire and became hard on cooling. He knew also that it would burn with a blue flame yielding copious vapours with a peculiarly offensive smell, which condensed into the strong acid Oleum Sulphuris per Campanum. ${ }^{23} \mathrm{He}$ also mentioned that true sulphur would make gunpowder with nitre and charcoal and, when heated with fixed alkali, would form "liver of sulphur", soluble in water with a smell of rotten eggs and the property of turning silver black. Despite the sound chemical evidence these tests would have supplied, their potential value for mineral water analysis remained generally unrecognized. Controversies about the presence or absence of sulphur, particularly in Bath waters, continued long after the publication of Shaw's Enquiry in 1734.

\section{THE ROLE OF “FIXED AIR" IN MINERAL WATERS}

In a century which saw the rise of pneumatic chemistry as well as a growing interest in spa treatments, it is not surprising to find attention given to the gaseous components of mineral waters. Besides, the great popularity of aerated waters in eighteenth-century medicine arose from the long-held belief that they offered an effective cure for bladder-stone and gravel. In fact, this had always been one of the main

\footnotetext{
${ }^{22}$ Shaw adopted Boerhaave's definition of salts, “. . . fossil bodies, fusible by fire, and congealable again by cold into little glebes or chrystals; soluble in water so as to disappear therein, and impressing a sensation of acrimony on the tongue", $\mathrm{H}$. Boerhaave, $A$ new method of chemistry; including the history, theory and practice of the art, translated from the Latin of Elementa chemiae, with notes and an appendix, by Peter Shaw, 2nd ed., 2 vols., London, 1741, vol. 1, p. 104. This definition was also adopted by Rice Charleton, see note 59 below.

${ }^{23} \mathrm{~A}$ mixture of sulphuric acid and sulphur dioxide made by burning sulphur in a large glass bell and dissolving the fumes in water; identical with "spirit of vitriol", Crosland, op. cit. (1962), note 6 above, p. 90.
} 


\section{N. G. Coley}

reasons for drinking mineral waters, although it had sometimes been questioned. ${ }^{24}$ Shaw suggested that the presence of volatile components in these waters could be revealed by placing half-filled thin-walled vials, or bladders, in hot water to see whether they would expand or burst. ${ }^{25} \mathrm{He}$ knew that "airs" could sometimes be driven out of mineral waters by adding acids, Rhenish wine, or sugar, and that they could be extracted and collected in the exhausted receiver of an air-pump. He suggested that the weights of such volatile components could be found by weighing them in bladders, making allowance for the effects of atmospheric buoyancy, but he proposed no chemical tests for them, supposing them to be nothing more than common air. ${ }^{26}$

Few English mineral waters contain noticeable quantities of gases, although the Bristol Hotwell was an exception. Despite its awkward situation near to sea-level and the close proximity of Bath, the Bristol water became very popular in the eighteenth century and was frequently analysed by local physicians and chemists. Among these was Alexander Sutherland, a Bath physician who analysed the Bristol water in 1758 with the aid of his colleague William Baylies. ${ }^{27}$ After briefly reviewing all the earlier works of importance on the Hotwell water since Edward Jorden first mentioned it in 1632, Sutherland maintained that it ought to be possible to determine its chief ingredients more reliably than hitherto. He criticized those who claimed to identify the chemical contents of the water from its medicinal qualities real or imagined, rather than on the results of routine analysis, whilst he said those who had declared this water to be a simple elementary substance based their opinion on ignorance. Yet others who charged the water with iron, alum, sulphur, and other things which it did not contain, either stated an opinion without making experiments, or erred in their analyses. Shunning all of these approaches, Sutherland determined to follow Shaw, taking "... nothing on trust ... all we know must be founded on experiments ... we may be allowed to reason, so long as we pretend not to certainty, or pass our opinion for demonstration." 28 He disagreed with those who saw no point in chemical analysis, but he did share popular doubts about the possibility of making a complete and exact analysis because, "Mineral waters are so nicely compounded by Nature, that the most accurate Analysis can never comprehend the exact proportions of their impregnation, some parts are volatile, while others, by the fire, and other mediums, undergo such changes as never existed in the Compound ...". ${ }^{29}$

The possibility that strong heat might change or destroy the ingredients of mineral waters had long inhibited attempts to analyse them, but this was not the only factor

\footnotetext{
24 For example, John Quinton, physician to the Earl of Manchester, suggested that the waters sometimes caused the gravel and stones they were supposed to cure, Practical observations in physick, but especially on the nat ure of mineral waters and metallick medicines, London, 1711, p. 14.

${ }^{25}$ Shaw, op. cit., note 19 above, p. 74.

${ }^{26}$ For a study of Shaw's contributions to this aspect of mineral water analysis, see Jon Eklund, 'Of a spirit in the water: some early ideas on the aerial discussion', Isis, 1976, 67: 527-550.

${ }^{27}$ A. Sutherland, The nature and qualities of Bristol Water, illustrated by experiments and observations with practical reflections on Bath Waters occasionally interspersed, London, (Bristol printed), 1758. For Baylies see, Munk, op. cit., note 17 above, vol. 2, pp. 271-272; DNB, vol. 1, p. 1367; E. A. B. Barnard, An eighteenth century Worcestershire doctor: W. Baylies of Evesham, 1724-1789, Worcester, 1946.

28 Sutherland, op. cit., note 27 above, p. 11.

29 George Randolph, An enquiry into the medicinal virtues of Bristol Waters and the indication of cure when it answers, Oxford, 1745, (2nd ed., 1750), quoted in Sutherland, op. cit., note 27 above, p. 27.
} 


\section{Physicians and the chemical analysis of mineral waters}

which had tended to discredit mineral water analysis. For example, John Shebbeare, a Bristol chemist, had claimed in 1740 that the Hotwell water contained alum and "lime in the act of slaking". ${ }^{30}$ Sutherland poured scorn on this idea, remarking that some analysts wished to promote the use of particular springs mainly for financial reward. Shebbeare, said Sutherland, thought that alum and lime were good for diabetes and so he had claimed falsely that they were present in this water.

From the results of his own analysis, Sutherland concluded that the Bristol Hotwell contained six principal constituents, viz., the pure element (water), the spirit (gases), a vitriolic acid, a marine acid, and a calcareous earth, but when he discussed the medicinal qualities of the water he reverted to the traditional ideas of the four-element theory. "To sum up the whole," he wrote, "much may be due to the water, as a simple Fluid, something to its Temperature, something to the Salts, something to its Earth, but most of all, to the subtle Mineral Acid-Spirit." ${ }^{31}$ Charles Lucas had related this mineral spirit directly to the universal acid, "... subtilized and volatilized by some portion of inherent phlogiston". ${ }^{32}$ According to Lucas, both the universal acid and the phlogiston came from the decomposition of pyrites in the depths of the earth.

The notion that the volatile parts of mineral waters originated in the earth had earlier led William Brownrigg, the Whitehaven physician and chemist, to suggest that a study of the "damps" of mines "... might lead to a discovery of the nature and origins of the subtile and volatile principles, which enter the composition of various mineral waters, and are stiled their spirit; on which their chief virtues are found to depend." ${ }^{33}$ Brownrigg recalled that Shaw had obtained a large quantity of air from Scarborough water, and he also knew that Francis Home, the professor of materia medica at Edinburgh, had collected air from the water of Dunse Spaw. ${ }^{34}$ Both, thinking they were dealing with common air, had been content to measure only its volume and made no further tests, although Hoffmann had insisted that the mineral spirits dissolved in natural waters should not be confused with ordinary air.

In some experiments on the gases evolved from the water of Pouhon Spa, Brownrigg recognized "... that most subtle and active exhalation, which, in many places, perspires from springs and lakes, and other openings of the earth; or arises in

${ }^{30} \mathrm{~J}$. Shebbeare, $A$ new analysis of the Bristol Waters together with the cause of the diabetes and hectic. And their cure, as it results from the waters experimentally considered, London, 1740, quoted in Sutherland, op. cit., note 27 above, p. 26. Shebbeare later became a notorious political writer and novelist, DNB, vol. 18, pp. $1-4$.

${ }^{31}$ Sutherland, op. cit., note 27 above, p. 98. Shaw, too, claimed four principles in mineral waters, viz., the water itself, saline parts, earthy parts, and an "aether, air or mineral spirit" (P. Shaw, $A$ dissertation on the contents, virtues and uses of cold and hot mineral springs, particularly those of Scarborough, in a letter to Robert Robinson, Esq., Recorder of that Corporation, London, 1755, pp. 5-10).

${ }^{32}$ C. Lucas, An essay on waters in three parts ..., London, 1756, part 2, p. 213.

${ }^{33}$ W. Brownrigg, Phil. Trans. R. Soc. Lond., 1765, 55: 218-243. A first version of this work had been read at meetings of the Royal Society in 1741-42, Journal Book $R$. Soc. Lond., vol. 17 (1739-42), pp. 375 (11 March 1741), 394 (8 April 1742), 404 (13 May, 1742). Brownrigg visited Scarborough Spa in 1764. For Brownrigg, see Joshua Dixon, MD., the Elder, (a pupil of Brownrigg), The literary life of William Brownrigg, MD., FRS., to which is added an account of the coal mines near Whitehaven, London, 1801; DNB, vol. 3, p. 85; DSB, vol. 2. (1971), p. 523; J. R. Wood, Ann. Sci., 1950, 6: 186-196, 436-444; 1951, 7: 77-94, 199-206. J. V. Beckett, Notes Rec. R. Soc. Lond., 1977, 32: 255-271.

${ }^{34} \mathrm{~F}$. Home, An essay on the contents and virtues of Dunse-Spaw . ., Edinburgh, 1751, p. 99. For Home, see $D N B$, vol. 9, p. 1123. 


\section{N. G. Coley}

pits and mines, where it is discovered by extinguishing flame." 35 This was the notorious "choak damp" [sic], and Brownrigg thought that it gave to Pyrmont and Spa waters, as well as other acidulae, their principal medicinal virtues and sharp taste. ${ }^{36}$ He devised an apparatus in which this gas could be expelled from the water and collected. It was necessary to boil the water to expel all the gas, after which it had no acid taste and no effect on tincture of galls. Brownrigg noticed that as the gas escaped the mineral water became turbid, and concluded "... that this aerial fluid is closely united to the other principles of which this water is composed . . in proportion as this mineral air is separated by heat, in the same proportion the more gross earthy parts of the water seem also to separate from it." (Plate 1.) ${ }^{37}$

Before he could pursue these experiments further, however, Henry Cavendish published an account of the water from a pump in Rathbone Place in London, in which he showed that with the release of the gases from the water a sediment consisting of calcareous earth with a small proportion of magnesia was deposited. The gases were found to be a mixture of fixed air with common air in proportions similar to those discovered by Brownrigg. ${ }^{38}$ Cavendish also noted that whilst lime itself was only slightly soluble in water, when saturated with fixed air it became totally insoluble, but with twice this quantity of fixed air the lime became readily soluble. This curious property was further investigated by the London apothecary, Timothy Lane. ${ }^{39}$

The well-known deposition of an ochre-coloured sediment accompanied by the loss of iron by chalybeate waters had often been ascribed to a "volatile vitriol"' for lack of a more precise explanation, but Lane now showed that the volatile component was really fixed air, and he went on to say, "It appears to me highly probable, that fixed air is generally necessary to the impregnation of mineral springs. That by the right knowledge of this principle, we may now solve most difficulties that have arisen on this subject, and very probably be able hereafter, to imitate nature, in the formation of medicated waters ...".40

Brownrigg returned to his experiments on the Pouhon water in 1774, after others, including Priestley, had shown interest in the subject. He now showed that freezing the water as well as boiling it served to precipitate its earth and drive out its fixed air. In fact, "this mephitic air is the medium by which the metalline and absorbent earths contained in the Pouhon water are therein held in solution". ${ }^{41}$ Notably, there was the combination of fixed air with the "martial earth" in chalybeate waters which were especially difficult to keep or transport. It has been the practice to add a small

\footnotetext{
${ }^{35}$ Brownrigg, op. cit., note 33 above, p. 219.

${ }^{36}$ Brownrigg was probably the first to recognize that fixed air is an acid, although the fact that it would not redden litmus left him in some doubt. He received the Copley Medal of the Royal Society for his work on Spa water in 1756.

${ }^{37}$ Brownrigg, op. cit., note 33 above, p. 227.

${ }^{38}$ H. Cavendish, Phil. Trans. R. Soc. Lond., 1767, 57: 91-108.

${ }^{39}$ In a letter from Mr. Lane, Apothecary in Aldersgate Street, to the Hon. Henry Cavendish, FRS., on the solubility of iron in simple water, by the intervention of fixed air, Phil, Trans. R. Soc. Lond., 1769, 59: 216-227.

${ }^{40}$ Ibid., p. 225 . Attempts to prepare artificial mineral waters had been made since the mid-seventeenth century, Coley, op. cit., note 2 above, p. 205.

${ }^{41}$ Brownrigg, Phil. Trans. R. Soc. Lond., 1774, 64: 357-371, see p. 362.
} 


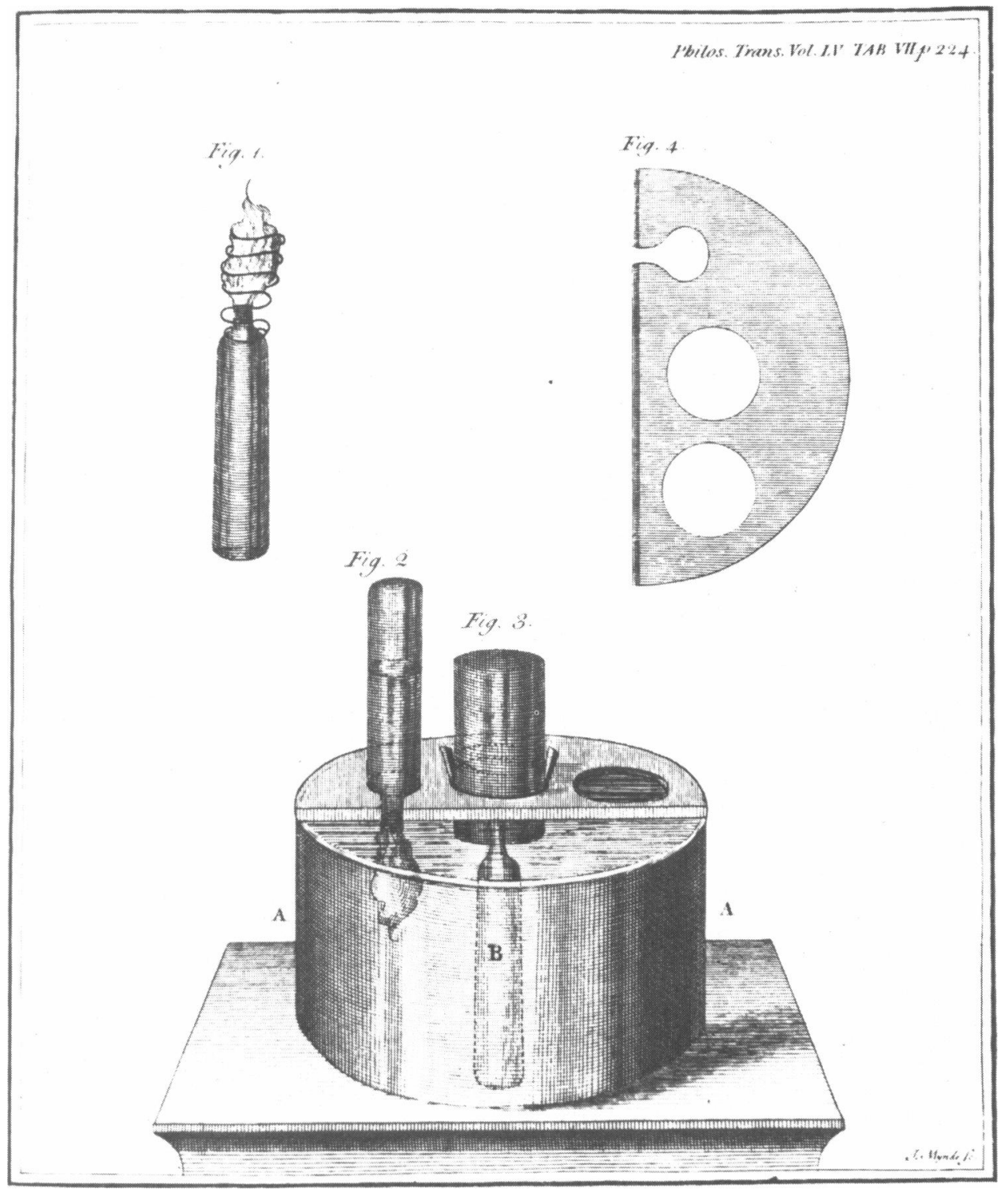

Plate 1. Brownrigg's apparatus for collecting the gases contained in Pyrmont water. (Phil. Trans. R. Soc. Lond., 1765, 55: 224.) 


\section{Physicians and the chemical analysis of mineral waters}

quantity of dilute sulphuric acid to these waters to prevent the deposition of their iron, but this, according to Brownrigg, was a mistake because the acid destroys rather than preserves these waters, "by expelling their elastic spirit, and entering into new combinations with their earthy principles: thereby forming a new compound, less perishable indeed than the former, but also less efficacious in the cure of many diseases ...".42 In some natural chalybeates, however, the iron was found to be held in solution partly by fixed air and partly by vitriolic acid. These waters would deposit an ochry sediment on standing, yet continued to give a positive reaction for iron even after boiling. ${ }^{43}$

\section{THE SULPHUR CONTROVERSY AT BATH}

The waters at Bath, England's most fashionable spa, were examined many times during the eighteenth century yet their chemical composition remained uncertain and figured in bitter disputes between rival physicians, who disagreed both about the chemical contents of the waters and their medicinal effects. William Falconer remarked in $\mathbf{1 7 7 0}$ that these disputes had arisen from four main causes. In the first place, he said, there was inadequate chemical knowledge amongst those who had examined the waters; second, coupled with this the terms used were confused and ambiguous. Third, there was a need for a sound, reliable method of analysis, and finally there was the financial reward. ${ }^{44}$ In eighteenth-century Bath this was a strong motive; there were rich pickings to be had by physicians who could promote their own professional reputations at the spa.

Arguments about the nature and proper use of Bath waters had persisted since the seventeenth century in books, tracts, and pamphlets in which the chief point of dispute concerned the presence or otherwise of sulphur in the waters. In 1632, Edward Jorden had written, "I will not deny some touch of sulphur in them [i.e., Bath waters] . . but the proportion of sulphur to bitumen is very little", and his editor, Thomas Guidott, who like Jorden was also a physician at Bath, later agreed with this opinion. ${ }^{45} \mathrm{On}$ the other hand, John Mayow, who practised medicine at Bath only during the bathing "season", denied the presence of sulphur. In 1674, he wrote, "As for nitre and sulphur, with which it has been hitherto supposed that the Bath thermal waters are impregnated, I think that neither of them exists dissolved in the water of these springs." 46

In the eighteenth century, these disputes continued, partly due to inconclusive chemical observations and confusion over the meaning and use of the term "sulphur"

\footnotetext{
${ }^{42}$ Ibid., p. 366. Yet this expedient was still being recommended forty years later. For example, Tunbridge Wells water could not be transported without depositing its iron, and patients were advised "... that by the addition of oleum sulphuris and vitriol it may be carried to and drunk at a distance with equal advantage..." (A descriptive guide of Tunbridge Wells and its environs, Tunbridge Wells, J. Clifford, 1818).

${ }^{43}$ T. Houlston, Essay on the Liverpool Spa water, Liverpool, 1773.

4 W. Falconer, An essay on Bath Waters, London, 1770, pp. 6-15.

45 Jorden, op. cit. (1632), note 5 above, p. 65; revised ed., edited with an appendix by T. Guidott, London, 1669 , appendix, p. 54.

${ }^{46}$ J. Mayow, Tractatus quinque ...,London 1674 (reprinted, Edinburgh, Alembic Club Reprints, 1957, no. 17 , p. 171).
} 


\section{N. G. Coley}

and partly arising from the professional rivalries between physicians, surgeons, and apothecaries. The resident physicians at Bath, led by William Oliver, considered that their knowledge of the nature and proper use of Bath waters was superior to that of the surgeons and apothecaries of the town, and more especially to that of physicians who came to Bath to practise medicine only during the bathing season. Oliver contended that doctors who lived at a distance and those who were themselves no more than visitors to the town could have only an imperfect understanding of the proper use of the waters and of their effects on patients. ${ }^{47}$ Long experience, he said, had shown that, when properly applied, Bath waters would cure gout, palsy, rheumatism, and skin complaints, although it was usual for physicians to prescribe additional medicines to be purchased from apothecaries and taken with the waters. Rivals sometimes denied that Bath waters alone had any more real value than ordinary water, and consequently the medical fraternity in Bath, conscious of the financial privileges which they derived from the reputation of the waters, tended to close ranks against outsiders. ${ }^{48}$ The exclusiveness of medical practice in the city was further enhanced by the fact that the mineral springs, pump room, and hospital were all controlled in various ways by the Corporation, and some suspected that there was actually a conspiracy to prevent chemical investigation of the waters and so maintain the tradition that their medicinal virtues depended upon their sulphur content. ${ }^{49}$

The most vigorous and outspoken critic of Oliver and his colleagues was the Irish physician Charles Lucas who, after spending a year touring the major European spas, arrived in Bath in 1753 and three years later published his Essay on waters, in which he asserted that the Bath waters did not contain sulphur as such, but that the properties commonly assigned to the "sulphureous principle" were chiefly due to phlogiston. Commenting on the fact that the term "sulphur" was used to mean a variety of substances, he suggested that this confusion covered much chemical ignorance. He proudly acknowledged his own apprenticeship to an apothecary, a circumstance which, along with his familiarity with the chemical work of Hoffmann and Boerhaave, emboldened him to lay claim to a superior knowledge of the chemical composition of mineral waters. ${ }^{50}$ His examination of the Bath waters led him to deny the traditional view that they were sulphureous, nitrous, saponaceous, and alkaline, and to assert instead that they contained a mild, volatile, vitriolic acid spirit combined with a subtle, penetrating, neutral salt - a mixture of sea-salt, iron, and earth. Moreover, he repeatedly linked the chemical composition of the waters with the

\footnotetext{
${ }^{47} \mathrm{~W}$. Oliver, A practical essay on the use and abuse of warm bathing in gouty cases, Bath, 1751 (2nd ed., 1753), pp. $2-4,40-44$.

${ }^{43}$ The number of medical men in Bath remained high throughout the eighteenth century. The Universal Magazine in 1747 listed twelve physicians, seven surgeons, and thirty-one apothecaries. Ten years later, W. Baylies (Practical reflections on the uses and abuses of Bath waters, London, 1757, p. xxiv) said there were “... no less than seventeen physicians and almost twice as many apothecaries". The strangers' assistant and guide to Bath (1773), ascribed to W. Falconer, also mentioned seventeen physicians, with ten surgeons and twenty-seven apothecaries, whilst the town directory for 1792 lists fifteen physicians, fifteen surgeons, and twenty-five apothecaries.

49 Letters of Dr. Lucas and Dr. Oliver, occasioned by a physical confederacy discovered in Bath, London, 1757. Falconer, op. cit., note 44 above, pp. 15-16, also hinted that there was resistance to the chemical analysis of Bath waters in case the results should diminish their reputation with patients.

${ }^{\text {so }}$ Lucas, op. cit., note 32 above, part 1, p. xviii.
} 


\section{Physicians and the chemical analysis of mineral waters}

organization of medical treatments at Bath, making no secret of his conviction that there were vested interests which, whilst seeking to perpetuate the mystique of the waters, maintained social and political control of the city. "For though they [the citizens of Bath] be many, their best privilege, such as that of electing magistrates, common council and representatives in parliament for the city, are absorbed by the Few - a political epidemic distemper in Britain and Ireland beyond the reach of physic, though seconded by Bath water!"'s1

Lucas's broad hints of a conspiracy and his allegations of ignorance about the chemical composition of the waters among medical men who derived the better part of their living from their use of these waters in treating patients, aroused Oliver's anger and encouraged others to join the argument. William Baylies, a physician who, like Lucas, had first been trained as an apothecary and consequently placed similar emphasis on the importance of chemical analysis, agreed that there was no sulphur in Bath waters. He was also critical of some of the medicines commonly prescribed for use with the waters. ${ }^{52}$ Thus, Oliver habitually used mercury preparations for skin complaints and Peruvian bark for rheumatic conditions, together with the traditional methods of bleeding, purging, and vomiting. Baylies alleged that the results of using such methods and shop medicines together with the waters themselves, must always leave doubts as to which form of treatment had the desired effect. He also suggested that it would be useful to isolate, examine, and use the salts extracted from Bath waters so as to control the dosages more exactly, increasing the patients' intake of the salts without prescribing larger volumes of the waters. Lastly, he said, in cases where neither the waters nor their constituent salts were desirable as medicines, it was dishonest to prescribe them for patients together with more appropriate shop medicines and then pretend that it was the waters which had worked a cure - waters which were available only in Bath. ${ }^{33}$ It is not surprising to find that, as a result of criticisms such as these, Baylies, like Lucas, was ostracized by Oliver and his colleagues and was ultimately obliged to leave Bath..$^{54}$

The argument in favour of sulphur in Bath waters was supported by Lucas's fellowcountryman, the Irish Quaker physician, John Rutty, who compiled an extensive survey of mineral waters based almost entirely on the observations and opinions of others. ${ }^{35}$ Rutty took issue with Lucas and concluded that, "The Bath water therefore maintains its title to the powerful effects ascribed to it, not merely from the active heat, nor merely from the ingredients common to it and any more purging chalybeate water ... but also from a sulphureous impregnation." 56 To this Lucas replied with some justification that Rutty had not himself analysed the Bath waters at their source

\footnotetext{
s1 Ibid., part 3, p. 244.

32 Baylies, op. cit., note 48 above, pp. xix, 62-72.

53 Ibid., pp. 1-34. There was relatively little export of Bath waters compared with the extensive international trade in Bristol waters in the eighteenth century (S. MacIntyre, J. Transp. Hist., 1973, N.S. 2: $1-19$, see pp. 12, 13).

${ }^{54} \mathrm{~W}$. Baylies, $A$ narrative of facts, demonstrating the actual existence and true cause of that physical confederacy in Bath, made known to the public in the printed letters of Dr. Lucas and Dr. Oliver, Bath, 1757. Baylies left England soon afterwards, and later became physician to Frederick the Great.

ss J. Rutty, A methodical synopsis of mineral waters, London, 1757.

s6 Idem, The argument of sulphur or no sulphur in waters discussed, London, 1762, p. 43.
} 


\section{N. G. Coley}

and therefore could not speak from first-hand knowledge about their chemical contents. ${ }^{37}$ This charge could not, however, be brought against some other protagonists in the dispute. Thus, Sutherland claimed to have found sulphur in Bath waters - a convenient distinction between these and the Bristol Hotwell water, ${ }^{58}$ whereas Rice Charleton, Oliver's collaborator at the Bath Hospital, first analysed the waters in 1754 and reported the presence of iron, an earth, common sea-salt, a neutral salt, elementary fire, and a bituminous matter, but no sulphur. ${ }^{59}$ Charleton repeated his analysis in 1776, when he compared his results with those of Falconer, who had asserted that the waters contained a hepar sulphuris cum calce viva (i.e., calcium sulphide), from the taste and smell of the waters and the bluish-white coloration produced on the addition of acids. ${ }^{60}$ Like Falconer, Charleton thought that most of the confusion had arisen from ambiguity over the meaning of the term "sulphureous principle"". Lucas had emphasized the similarity between sulphur and phlogiston, but Charleton's experiments seemed to confirm the view first expressed by Jorden that the so-called sulphur of Bath waters was really a volatile bituminous material. Charleton's method was to prepare mixtures of sulphur in water and compare their reactions towards mercurous chloride and silver nitrate with the similar reactions of Bath waters. He found that none of the precipitates formed by the latter would burn when dropped on to a red-hot iron plate, whereas all the residues from the sulphur water mixtures burned with a blue flame. Then on evaporating the Bath waters to obtain the dry residue, Charleton found "... an exceeding fine aromatic balsam entirely dissimilar from common brimstone." 61

Besides attempting to settle the question of sulphur, Charleton also introduced a simple colorimetric procedure for iron based on the same principle of comparing the reactions of prepared solutions with those of the natural waters, since "it becomes a matter of no great difficulty, by preparing an artificial chalybeate water, in which a known proportion of this metal is dissolved, to determine how much of it exists in the natural one, that where two waters strike the same colour with equal quantities of galls, that each must contain the same quantity of iron." ${ }^{62}$ To discover whether or not the chalybeate principle was volatile as was often claimed, Charleton mixed the steam evolved from the Bath water with tincture of galls. No blue coloration was observed, and Charleton concluded that the chalybeate principle was not volatile, yet he knew that many such waters lose their iron when exposed to the air. He mentioned Stephen Hales's explanation of the precipitation of iron due to the effects of the random

${ }^{37} \mathrm{C}$. Lucas, A cursory examination of the methodical synopsis of mineral waters and of the argument of sulphur or no sulphur in waters discussed ..., Dublin, 1763.

${ }^{88} \mathrm{~A}$. Sutherland, An attempt to ascertain and extend the virtues of Bath and Bristol waters by experiments and cases, 2nd ed., London, 1764.

${ }^{39} \mathrm{R}$. Charleton, Three tracts on Bath Water: Tract the first; $A$ chymical analysis of the Bath Water, 2nd ed., Bath, 1776. This was a revision of an earlier work published in 1754, (note 61 below). For Charleton, see Alumni Oxonienses, later series, (1715-1886), 4 vols., Oxford University Press, 1891, vol. 1, p. 240.

${ }^{60}$ Falconer, op. cit., note 44 above, pp. 154-172. The term hepar was used by Guyton de Morveau in 1777 to replace the older liver of sulphur, Crosland, op. cit. (1962), note 6 above, p. 153.

${ }^{61}$ Charleton, op. cit., note 59 above, p. 30. This description was first given by Charleton in his earlier work, $\boldsymbol{A}$ treatise on the Bath Waters: wherein are discovered the several principles of which they are composed; the cause of their heat; and the manner of their production, Bath, 1754, p. 39.

${ }^{62}$ Charleton, op. cit., note 59 above, p. 6. 
motion of the particles of air and water, ${ }^{63}$ but, like many of his contemporaries, he preferred the "safer" ground of the four-element theory and suggested that "what these Bath waters principally lose when they are withdrawn from their spring, is their elementary fire." This resulted in an increase in specific gravity, causing the particles to approach more closely with consequent irreversible changes in their arrangement. The fact that he repeated this view in the second edition of his book (the first had appeared in 1754) indicates a lack of knowledge about contemporary developments in mineral water analysis. Had he understood the significance of the results obtained by Brownrigg, Cavendish, and Lane, he would surely have questioned a view which by 1776 had been superseded.

\section{DEVELOPING ANALYTICAL TECHNIQUES}

While Friedrich Hoffmann was the mentor of mineral water analysts in the early decades of the eighteenth century, Torbern Bergman, the Swedish chemist, exercised a strong influence in this and other branches of chemistry during the last two decades. In his Opuscula, published between 1779 and 1783, Bergman devoted a long section to water analysis of all kinds, including the special problems of mineral waters. ${ }^{64}$ Bergman was doubtful about some of the reagents in common use, and suggested that salited lime (calcium chloride), alum, corrosive sublimate, mercury nitrate, and lead acetate should be dispensed with altogether. He was also suspicious of syrup of violets as a test for acidity because it could become red automatically if it fermented, and would turn green with iron as well as with alkalis. He used the traditional tincture of galls for iron, but also introduced a new reagent "phlogisticated alkali", which he prepared by boiling an aqueous mixture of prussian blue and alkali, saturating with acid and filtering. The resulting solution gave a delicate precipitation test for iron (prussian blue), copper (brown), and manganese (white). Oxalic acid, he regarded as one of the most sensitive tests for lime, and silver nitrate in distilled water as the most complete test for chlorides. Bergman also endorsed the view that fixed air, which he called the "aerial acid" was the most important constituent in mineral waters, claiming that this was shown by the fact that the expulsion of the elastic fluid caused the water to lose its acidity "which it recovers altogether, when the loss of that elastic fluid is supplied ...".65

For Bergman, analysis was always to be confirmed by subsequent synthesis. When all the constituents of a mineral water had been identified and their proportions found either by weighing them directly or by calculating their weights from the weights of precipitates, an artificial mixture was to be made in exactly the same proportion. Only when such a mixture could be shown to have properties identical with the natural water could it be assumed that a complete and reliable analysis had been made.

\footnotetext{
${ }^{63}$ S. Hales, Philosophical experiments . . . shewing how sea-water may be made fresh and wholesome... To which is added, an account of several experiments and observations on chalybeate or steel-waters, London, 1739, p. 105; quoted by Charleton, op. cit., note 59 above, p. 15.

o4 T. Bergman, Opuscula physica et chemica..., 3 vols, Uppsala, 1779-83; Eng. trans., by Edmund Cullen, Physical and chemical essays, 2 vols., London, 1784 and 1788 (vol. 3, Edinburgh, 1791), vol. 1, pp. 91-303.

${ }^{65}$ Ibid., vol. 1, p. 151.
} 


\section{N. G. Coley}

"Hence forward, let us rely on no analysis, until a mineral water, in every respect resembling the natural water, has been recomposed, with pure water and the substances that have been obtained."66 Few eighteenth-century physicians would have been prepared to place this degree of confidence in the results of chemical tests on artificially prepared mixtures, although one object of analysis had long been to make the preparation of artificial mineral waters possible. Nevertheless, Bergman's analytical methods were closely followed by many physicians. Thus, Sir John Elliott, physician to the Prince of Wales, used Bergman's methods and also gave instructions for preparing artificial mineral waters at home with ordinary domestic utensils. ${ }^{67}$

To reduce the quantitative errors which arose from the great dilution of natural waters, Elliott began with very large volumes to which he added a good excess of the reagent. The mixture was then allowed to stand for twenty-four hours before filtering. Solid residues were extracted by evaporating several hundred pounds of the water to dryness, and, after weighing, the residues were examined by Bergman's method. ${ }^{68}$ The first stage was to digest the residue with three to four times its own weight of spirit of wine, filter, dry, and weigh the insoluble residue. Next, cold distilled water, about eight times the weight of this residue was added, and, after shaking, the mixture was again filtered and the insoluble residue dried and weighed. Finally, the residue was boiled with 500 to 600 times its own weight of distilled water, and the mixture cooled and filtered. This last residue was then dried, weighed, and examined, along with the solutions from each of the earlier stages of the process. ${ }^{69}$

Elliott explained that the first alcoholic solution would contain calcium and magnesium chlorides which could be separated by evaporating to dryness, dissolving the residue in pure water, and adding dilute sulphuric acid. Selenite (calcium sulphate) would be precipitated, and Epsom salt would remain in solution from which it could be crystallized. The cold water solution would contain neutral salts and alkaline or earthy bases together with "martial vitriol" (ferrous sulphate), and these substances might be crystallized separately by careful evaporation. Anything dissolved at the boiling stage would be selenite, and the final residue would contain calcareous earth, aerated magnesia, or iron, clay, and quartz. Iron and clay (alumina) in this residue could be dissolved in hydrochloric acid, from which the iron could be precipitated by prussian alkali and clay by vegetable alkali. Any remaining matter must be quartz, for which Bergman had recommended the blowpipe. ${ }^{70}$

o6 Ibid., p. 215. Fourcroy made the same point, A. F. Fourcroy, Leçons élementaires d'histoire naturelle et de chimie ..., 2 vols., Paris, 1782, vol. 2, p. 406.

${ }^{67} \mathrm{~J}$. Elliott, An account of the nature and medicinal virtues of the principal mineral waters of Great Britain and Ireland; and others most in repute on the Continent. To which are prefixed directions for impregnating water with fixed air... in order to communicate to it the peculiar virtues of... mineral waters ..., London, 1789.

68 Bergman, op. cit., note 64 above, vol. 1 (1784), pp. 159-160.

${ }^{69}$ Elliott, op. cit., note 67 above, pp. 110-112.

${ }^{70}$ This procedure for analysis was widely adopted, see for example J. A. Chaptal, Élémens de chimie, 3 vols, Paris, 1790; Eng. trans., by W. Nicholson, Elements of chemistry, 3 vols., London, 1791 (2nd ed., 1795), vol. 1 (1795), pp. 293-294; T. Garnett, A treatise on the mineral waters of Harrogate containing the history of the waters, their chemical analysis, medicinal properties and plain directions for their use, Bradforth [sic], 1792 (2nd ed., 1794), p. 6; the use of large volumes of the water and allowing the mixtures to stand for twenty-four hours was described by Fourcroy, op. cit., note 66 above, pp. 359-406. 


\section{Physicians and the chemical analysis of mineral waters}

The practical difficulties in carrying out such procedures are obvious and Bergman had himself pointed out likely sources of error. He was aware that some substances interfere with each other when they are present together in the same solution and "The various salts, although very different from each other when once mixed together, are not easily separated; hence often arises considerable difficulty in the analysis of waters ...". ${ }^{71}$ Thus, in a solution containing alum and Epsom salt, chalk would precipitate the alum alone, whereas quicklime would precipitate both. Again, it was hard to identify uncombined mineral alkali in the presence of common salt. In this case, Bergman used a simple titrimetric method in which the mixture was weighed and then just saturated with dilute sulphuric acid. Another exactly equal quantity of the acid was then neutralized with mineral alkali and the resulting solution was fully crystallized to find the weight of salt crystals formed. From this the weight of alkali in them was calculated, and by subtracting this from the weight of the original mixture the common salt in it could be found. ${ }^{22}$ These and other similar practical problems led the French chemist, Fourcroy, to issue a warning about the reliability of reagents, ${ }^{73}$ whilst in 1790 Thomas Garnett, then a physician in Harrogate, wrote, "However exact we may be in our investigations, and whatever degree of purity is possessed by different substances which we mix with the mineral waters in order to discover their principles; if it be granted that each test is capable of indicating two or three different matters, dissolved in the waters, a doubt will always remain concerning the result of their actions."74

If tests with reagents in solution were open to question, evaporation to dryness was also a doubtful process which could lead to chemical changes so that the residue no longer contained the same substances as the original water, and Garnett warned that the mineral water analyst should not rely solely on either category, "Yet by a judicious and careful use of both, we may, in general, ascertain with considerable accuracy, the principles contained in mineral waters." 75 Garnett thought that prior to Bergman no-one had given even tolerably accurate results, but this was due to "the very low state of chemical knowledge, together with the many difficulties which attend the examination of mineral waters which is undoubtedly the most difficult part of chemistry."76

A decade earlier, Joshua Walker, physician to Leeds Infirmary, had published some

"Bergman, op. cit., note 64 above, vol. 1 (1784), p. 171.

12 Ibid., p. 175. Simple volumetric methods such as this were common in the late eighteenth century. E. Rancke Madsen, The development of titrimetric analysis till 1806, Copenhagen, G.E.C. Gad, 1958, pp. 73-74; Szabadvàry, op. cit., note 2 above, p. 204.

${ }^{73}$ Fourcroy, op. cit., note 66 above, vol. 2, p. 360.

${ }^{4} \mathrm{~T}$. Garnett, Experiments and observations on the Horley Green Spaw, near Halifax..., Bradford, 1790, p. 4. For Garnett, see DNB, vol. 7, p. 886; DSB, vol. 5 (1972), p. 276; T. Garnett, Popular lectures on zoonomia, or the laws of animal life in health and disease, London, 1804 (memoir prefixed); $\mathrm{H}$. BenceJones, The Royal Institution, its founder and first professors, London, 1871, pp. 162-172.

${ }^{75}$ Garnett, op. cit., note 74 above, p. 6.

${ }^{76} \mathrm{Garnett}$, op. cit., note 70 above, p. 5. Another problem of accuracy arose from differences in the sizes of units of measurement bearing the same name. Donald Monro ( $A$ treatise on mineral waters, 2 vols., London, 1770, vol. 1, preface) complained "... it is not always easy, from accounts given by different authors, to ascertain the exact proportions of the different solid matters got by a chymical analysis from mineral waters; for the weights and measures of the same name are different in different countries, nay often in the same country". 


\section{N. G. Coley}

analyses of Harrogate waters made in the period from 1770 onwards. ${ }^{77}$ Influenced by Black, Hales, Brownrigg, and Cavendish, Walker recognized the role of fixed air in mineral waters and among their common constituents named vitriolic acid, fossil and vegetable alkalis, salts, earths, and metals. He distinguished Glauber's from Epsom salt by adding potassium carbonate which gave a white precipitate with the latter but not with the former. Like Bergman and Fourcroy, Walker allowed each mixture of mineral water and reagent to stand for twenty-four hours to ensure complete precipitation, and he also compared the results of tests on the mineral water with similar tests using pure water. Walker's work, though thorough, was grounded in the traditional methods used by physicians to demonstrate the value of mineral waters in the treatment of common complaints; it appeared at a time when mineral water analysis was developing rapidly in the hands of the chemists, who were already beginning to achieve more accurate results. ${ }^{78}$

Thomas Garnett, who was interested in the chemical problems of mineral water analysis, also followed Bergman's methods. ${ }^{79}$ In the sulphur water of Harrogate he found both sulphides and chlorides, a quantity of lime, but no iron and only a small amount of sulphate. The gases expelled from a measured volume of this water by boiling amounted to a total of $34 \mathrm{cu}$. ins. in a wine gallon, and he found that it was a mixture of carbonic acid, hydrogen sulphide, and a "permanent vapour" similar to that discovered by Pearson in Buxton water.$^{80}$ Garnett's analyses of this and the other Harrogate waters (Table II) were the best available until A. W. Hofmann's work in the mid-nineteenth century. ${ }^{81}$

\section{CRITICS OF BERGMAN}

Whilst Bergman's work on mineral water analysis was undoubtedly an advance on anything which had gone before, it still left room for improvement. Fourcroy suggested that some of Bergman's reagents were unnecessary and reduced the list to eleven. ${ }^{82} \mathrm{His}$ list included syrup of violets despite Bergman's distrust of it, but he did not cite the oxalic acid test for lime and its salts. Fourcroy criticized Bergman for lack of method in the use of his reagents and proposed a graduated series of tests beginning with lime water to precipitate carbonic acid and its salts as well as salts of magnesia,

\footnotetext{
$" \mathrm{~J}$. Walker, An essay on the waters of Harrogate and Thorpe Arch . . to which are prefixed observations on mineral waters in general and the method of analysing them, London, 1784. Walker relied on the accuracy of Falconer's Essay, op. cit., note 44 above, and also used Richard Watson, Chemical essays, 2 vols., Cambridge, 1781, vol. 3 (1783) (vols. 4 (1786) and 5(1787) were not then available).

${ }^{78}$ Garnett, op. cit., note 70 above, p. 24 , criticized the chemical part of Walker's book because, he said, "... we are not furnished with, by any means, an accurate analysis of the sulphur water."

79 He was also aware of Watson's analysis of the sulphur well made in July and August 1785 (R. Watson, Phil. Trans. R. Soc. Lond., 1786, 76: 171).

${ }^{80} \mathrm{G}$. Pearson, Observations and experiments for investigating the chymical history of the tepid springs of Buxton ..., 2 vols., London, 1784.

${ }^{81}$ A. W. Hofmann, Harrogate and its resources; chemical analysis of its medicated waters. Report addressed to the Chairman of the Harrogate Water Committee with an appendix on the modes of their administration..., London, 1854.

${ }^{82}$ Fourcroy, op. cit., note 66 above, vol. 2, pp. 359-406. Fourcroy's work on mineral water analysis is discussed in W. A. Smeaton, Fourcroy, chemist and revolutionary, 1755-1809, Cambridge, Heffer, 1962, pp. 112-118.
} 
TABLE II: DOCTOR GARNETT'S ANALYSIS OF THE HARROGATE WATERS (CALCULATED BY THE WINE GALLON)

\begin{tabular}{|c|c|c|c|c|c|c|c|c|c|c|c|c|c|}
\hline \multirow[b]{2}{*}{$\begin{array}{l}\text { Names } \\
\text { of the } \\
\text { Waters }\end{array}$} & \multirow[b]{2}{*}{$\begin{array}{l}\text { Spec. } \\
\text { Grav. }\end{array}$} & \multicolumn{3}{|c|}{ Cubic inches } & \multicolumn{3}{|c|}{ Grains } & \multicolumn{3}{|c|}{ Grains } & \multicolumn{3}{|c|}{ Grains } \\
\hline & & $\begin{array}{c}\text { Carbonic } \\
\text { acid } \\
\text { Gas }\end{array}$ & $\begin{array}{c}\text { Azotic } \\
\text { Gas }\end{array}$ & $\begin{array}{l}\text { Suplh. } \\
\text { Hyd. }\end{array}$ & $\begin{array}{c}\text { Muriat. } \\
\text { of } \\
\text { Soda }\end{array}$ & $\begin{array}{c}\text { Muriat. } \\
\text { of } \\
\text { Mag. }\end{array}$ & $\begin{array}{c}\text { Muriat. } \\
\text { of } \\
\text { Lime }\end{array}$ & $\begin{array}{l}\text { Carb. } \\
\text { of } \\
\text { Lime }\end{array}$ & $\begin{array}{c}\text { Carb. } \\
\text { of } \\
\text { Mag. }\end{array}$ & $\begin{array}{l}\text { Carb. } \\
\text { of } \\
\text { Iron }\end{array}$ & $\begin{array}{c}\text { Sulphat. } \\
\text { of } \\
\text { Mag. }\end{array}$ & $\begin{array}{c}\text { Sulphat. } \\
\text { of } \\
\text { Soda }\end{array}$ & $\begin{array}{c}\text { Sulphat. } \\
\text { of } \\
\text { Iron }\end{array}$ \\
\hline $\begin{array}{l}\text { Sulphur } \\
\text { Water }\end{array}$ & 1.0064 & 8.00 & 7.00 & 19 & 615.5 & 91 & 13 & 18.5 & 5.5 & & 10.5 & & \\
\hline $\begin{array}{l}\text { Crescent } \\
\text { Water }\end{array}$ & 1.002 & 20.80 & & 13 & 137.0 & 45 & & 3.1 & & 2.0 & 8.0 & & \\
\hline $\begin{array}{l}\text { Trewitt } \\
\text { Well }\end{array}$ & 1.00017 & 16.00 & 5.00 & & & & & & & 2.5 & & & 4.0 \\
\hline $\begin{array}{l}\text { Old } \\
\text { Spaw }\end{array}$ & 1.00014 & 15.75 & 4.25 & & & & & & & 2.0 & & 3 & 1.5 \\
\hline $\begin{array}{l}\text { St } \\
\text { George's } \\
\text { Spaw }\end{array}$ & 1.00012 & 13.50 & 3.50 & & & & & & & 2.0 & & & 4.5 \\
\hline
\end{tabular}

(From George Cayley, Synoptical tables, showing the component parts of the principal mineral waters, collected from the works of Doctor Saunders, Doctor Garnett, etc., Ripon, 1809.)

alumina, and iron. These were further identified by adding dilute sulphuric acid, when lime would form insoluble selenite and the rest would dissolve and could be recognized in solution by well-known properties. Fourcroy next used ammonia with a fresh sample of the mineral water to confirm his lime water test for magnesia, alumina, and iron. His third reagent was sodium hydroxide which also precipitated these three together with lime. The quantity of precipitate in this test was to be compared with that in the first, and then treated with dilute sulphuric acid as before. Next, he precipitated any chlorides and sulphates with silver nitrate, and, after filtering, the mixed precipitate was dried and added to water when the silver sulphate dissolved leaving the insoluble chloride. Lastly, he added a solution of mercurous nitrate, which also precipitated chlorides and sulphates, but in this case the dried precipitate was heated when the chloride sublimed whilst the sulphate decomposed to form a red calx. Fourcroy said that this arrangement of tests, together with an examination of the total residue from the mineral water by Bergman's method, could be made to yield more reliable information about the chemical contents and their proportions in the original water.

Six years later, however, in a lengthy monograph on the sulphur water of Enghien near Paris, Fourcroy showed that Bergman's method of examining the total residue was unreliable. ${ }^{83}$ Some of the chlorides of lime and magnesia, supposed to be com-

${ }^{83}$ Antoine François de Fourcroy and Jean Jacques Delaporte, Analyse chimique de l'eau sulfureuse d'Enghien. pour servir a l'histoire des eaux sulfureuses en général, Paris, 1788. This work was reissued as Traité complet des eaux minérales de la France, par Citoyen Fourcroy, Paris, 1792. Smeaton, op. cit., note 82 above, p. 220. 


\section{N. G. Coley}

pletely dissolved by the first addition of alcohol, were still present in the second extraction with cold water, whilst some common salt was found to dissolve in the alcohol. Thus, there was by no means a complete separation and the gravimetric results of this method were therefore suspect. On boiling the Enghien water, it was found that, although most of the hydrogen sulphide was driven off, the process was unsatisfactory because air in the apparatus reacted with some of the gas, producing a deposit of sulphur, and it also reacted with the mercury over which it was collected. A more reliable method was needed, and Fourcroy turned to reagents containing oxygen which would precipitate all the sulphur. These included strong nitric and sulphurous acids. Curiously, it was claimed that the latter precipitated only the sulphur in the mineral water and was preferred as a reagent to nitric acid. The sulphur was filtered off, dried, weighed, and the volume of hydrogen sulphide in the water was calculated using Bergman's observation that $60 \mathrm{cu}$. ins. (Swedish) of hydrogen sulphide contain 8 grains of sulphur. Some other reactions between hydrogen sulphide and metals, metal oxides, and salts were also described, but the precise chemical changes involved were not always clear. The problem of estimating the sulphur content of these waters continued to interest Fourcroy, but he made no significant improvements to his sulphurous acids method, and it was only in 1799 that a further refinement of the gravimetric procedure for sulphur was introduced by Richard Kirwan, ${ }^{84}$ who used nitric oxide to precipitate all the sulphur from a measured volume of mineral water and then calculated the quantity of hydrogen sulphide present from the weight of the precipitate. Kirwan regarded this as the only reliable method; he dismissed the use of concentrated nitric acid and pointed out that sulphurous acid precipitated its own sulphur as well as that of the hydrogen sulphide. As for oxy-muriatic acid (chlorine), another possible reagent for precipitating the sulphur, its oxidizing action was so strong that some of the sulphur was converted into the soluble sulphurous acid and so was lost from the precipitate. ${ }^{85}$

In his criticisms of Bergman's methods, Kirwan echoed Fourcroy's opinion that the tests had been applied haphazardly and had led to incomplete results. "They announce, it is true, some earthy or alkaline bases, others of them acids, and others also metals; yet they do not always inform us with what acid this or that basis is united, nor consequently the true nature of the matters contained in the waters ..." ${ }^{86}$ It therefore remained in the end for the analyst to use his knowledge of elective attractions to conjecture what earths and salts were actually present. In an effort to discover which acid was united to which base, Kirwan proposed a complicated procedure in which various different reagents were used to determine the concentration of each salt. ${ }^{87} \mathrm{He}$ also gave a list of "incompatible salts" which do not co-exist in solution in quantity, though he realized that at the dilutions common in mineral waters such salts may often occur together. Kirwan's explanation for this foreshadowed much later ionic and molecular theories of the mechanisms of solution; the acidic and basic parts of these salts were held in solution due to "... the resistance of the particles of water

${ }^{84}$ Kirwan, op. cit., note 15 above, pp. 194-196.

ss Ibid.

${ }^{86}$ Fourcroy, op. cit., note 83 above, p. 69, quoted by Kirwan, op. cit., note 15 above, p. 161.

${ }^{87}$ Ibid., pp. 97-129. The method is unreliable (Szabadvàry, op. cit., note 2 above, p. 117). 


\section{Physicians and the chemical analysis of mineral waters}

to that motion and separation from each other, which the action of the devellent [sic] powers of the saline particles would necessarily induce." the stronger the attraction of the salt particles to each other, the greater the dilution must be before they are counterbalanced by the resistance of the water particles keeping them apart. The attractions between vitriolic acid and barytes, marine acid, and silver, or fixed air and lime, Kirwan said, are so great that they act on each other even when they are present at no more than one part in 80,000 to 100,000 parts of water, and he suggested that it would be possible to draw up a table of such attractive powers (i.e., solubilities). ${ }^{89}$ In this way, Kirwan pointed out the relative insolubility of substances which could be precipitated from solution and so suggested that such reactions are never absolutely complete.

While the question of solubility required closer attention, evaporation methods were no more reliable, according to Kirwan. Fourcroy had already shown that when sulphur waters were evaporated to dryness a hepar could be formed by reaction between the sulphur and aerated lime. This would then dissolve in alcohol and the aerated lime in the original water would not be found. Further, when the alcoholic solution was evaporated to dryness the hepar could be oxidized to form sulphates such as selenite and Epsom salt, neither of which were present in the natural water.90 Kirwan also suggested that incompatible salts dissolved in the water might be precipitated by mutual reaction as the solution became more concentrated during evaporation, and the final residue would then contain compounds which were not present in the original water.

Kirwan was also critical of Bergman's quantitative methods, which he said were open to the objection that different states of hydration of the salts left in residues after evaporation were ignored. Kirwan thought it would be preferable to work on the basis of the anhydrous salts, rather than their hydrated forms as Bergman had done. One experiment in which this had led to unreliable results was Bergman's method for determining the quantities of soda and common salt in a mixture, because it was assumed that the quantities of water of crystallization and fixed air in the soda used to standardize the acid were the same as those in the soda mixed with common salt. Kirwan pointed out that since Bergman's work, others had suggested alternative methods of making such determinations with better accuracy. He particularly mentioned the curious blend of titrimetric and gravimetric procedures used by Gioanetti in analysing the waters of S. Vincent in Northern Italy. ${ }^{91}$

Kirwan's Essay was an important contribution to mineral water analysis which brought the progress of analytical techniques in this field up to date, although he did not introduce many innovations. Nevertheless, in his comprehensive, critical survey he

\footnotetext{
${ }^{88}$ Kirwan, op. cit., note 15 above, p. 140. Kirwan explained that he meant by "divellent" the powers which tended to effect decomposition and a new union, Phil. Trans. R. Soc. Lond., 1783, 73: 40; see also Partington, op. cit., note 7 above, vol. 3 (1963), p. 669; vol. 4 (1964), p. 572.

${ }^{89}$ Kirwan, op. cit., note 84 above, p. 17.

${ }^{90}$ Ibid., pp. 163-164, quoted from Fourcroy, op. cit., note 83 above, pp. 270 and 325.

9 V. A. Gioanetti, Analyse des eaux minérales de S. Vincent et de Courmayeur dans le Duché $d^{\prime}$ Aoste . ... Turin, 1779. For a discussion of Gioanetti's importance in the history of titrimetric analysis, see Madsen, op. cit., note 72 above, pp. 75-79, and Szabadvàry, op. cit., note 2 above, p. 204.
} 


\section{N. G. Coley}

emphasized the progress which had been made since about 1780 and showed how analytical methods might be further improved. It has been saici that Kirwan's chief objective was to make Bergman's methods quicker and simpler and this is no doubt true,, 92 but the overall effect of his work was more significantly to raise warnings about the problems of solution analysis, identify the weaknesses in existing methods, and discuss critically the new techniques by which some of these could be overcome. Kirwan threw fresh light on the approach to analysis by drawing attention to its theoretical basis and the need to attend to the chemical reactions involved as well as the practical problems of analytical technique. His Essay drew upon the best chemical work of the closing decades of the eighteenth century and began to lay foundations for the rapid expansion of analytical methods which marked the nineteenth.

\section{SUMMARY}

In this paper the chemical analysis of mineral waters during the eighteenth century is traced from the work of physicians such as Thomas Short and Peter Shaw, who followed the lead given by Friedrich Hoffmann, to the achievements of chemists such as Bergman, Fourcroy and Kirwan at the end of the century. The problems of obtaining reliable results were considerable, due to the great dilution of the waters and the close chemical similarities between many of their mineral solutes. Moreover, there were few reliable chemical tests and primitive notions about the formation and properties of natural minerals lingered on. Faced with the uncertainty of results derived from contemporary chemical procedures, physicians were prone to assert personal opinions often in opposition to each other. This led to acrimonious disputes such as the sulphur controversy at Bath, in which professional reputations were defended and other vested interests involved. There was also a growing interest in the gaseous components of mineral waters, especially the role of fixed air (carbon dioxide) which was investigated by Brownrigg, Black, Cavendish, and others who showed it to be an essential ingredient in nearly all natural waters.

In the closing decades of the century the problems of mineral water analysis were taken up by chemists such as Torbern Bergman, Fourcroy, and Richard Kirwan. Bergman critically examined the common chemical reagents and tests, discarding some and introducing new ones. Fourcroy criticized Bergman's methods and attempted to devise a systematic method of analysis which would give more reliable results. Richard Kirwan, who also criticized Bergman's methods, went on to examine the mechanism of double decomposition and the concept of relative solubilities, thus making a valuable contribution to the qualitative and quantitative interpretation of the results of solution analysis.

${ }^{92}$ Ibid., p. 114. 